\title{
Modeling the Liquid Phase Exfoliation of Graphene in Polar and Nonpolar Solvents
}

\author{
Rima Biswas 1,*iD \\ 1 Process Simulation Research Group, School of Chemical Engineering, Vellore Institute of Technology, Vellore, Tamil \\ Nadu, India 632014; rima.biswas@ @it.ac.in (R.M.); \\ * Correspondence: rima.biswas@ vit.ac.in (R.M);
}

Scopus Author ID 57191291744

Received: 4.10.2021; Revised: 5.11.2021; Accepted: 8.11.2021; Published: 24.11.2021

\begin{abstract}
Exfoliation is a promising technique to obtain graphene from graphite. The search for suitable exfoliation solvents is currently underway. The quality of the solvents used for spontaneous exfoliation is determined by a simple thermodynamic model. The model shows that the solvation energy of the organic solvents is higher for NMP $\left(-177.37 \mathrm{~mJ} \mathrm{~m}^{-2}\right)$ than other nonpolar solvents. It also shows that the solvation energy is correlated with sheet deformation and surface excess. Four groups of effective solvents are identified, including amine-, sulfoxide-, halogen-benzene-based solvents, in addition to cyclic structures with the oxygen atom. One can predict and screen potential solvents for spontaneous graphene exfoliation based on the reported mechanism.
\end{abstract}

Keywords: molecular simulation; spontaneous exfoliation; graphene; solvation energy; surface excess

(C) 2021 by the authors. This article is an open-access article distributed under the terms and conditions of the Creative Commons Attribution (CC BY) license (https://creativecommons.org/licenses/by/4.0/).

\section{Introduction}

Graphene is a single layer of carbon atoms that are located in the vertices of the hexagonal honeycomb lattice [1-4]. This material has excellent electrical, mechanical, and thermal properties that deeply impact many research areas and can be very useful in various applications, including electronic devices, chemical sensors, and nanocomposites [5-9]. A lot of methods have been developed to acquire graphene, but they can be simply classified into two major categories: the "bottom-up" and "top-down" approaches [10, 11]. An example of the former is chemical vapor deposition which produces thickness-controllable graphene but is limited by the high cost. In contrast, the example of the latter is chemical exfoliation which often involves three steps: formation of graphite oxide (GO) by oxidation, exfoliation of GO by sonication, and reduction of dispersed GO. Although this method was feasible and productive, oxidation may lead to a considerable deterioration of the graphene sheet. However, since the removal of oxygen-containing groups is not possible with the existing reduction methods, it is suggested to use a more physically intuitive method, which is liquid-phase exfoliation (LPE) [12-16]. This method is known to produce high-quality graphene by removing the graphite's oxygen-containing groups. For successful LPE, solvent plays a paramount role and can be aqueous or organic, including polymer solutions, surfactant solutions, and solutions of some other green dispersants [17-19]. The popular organic solvents include isopropanol $\gamma$-butyrolactone, $\mathrm{N}, \mathrm{N}$-dimethylformamide, tetrahydrofuran, and so forth [20-23]. It is believed that good solvents for graphene exfoliation should possess surface 
tension about $40-50 \mathrm{~mJ} \mathrm{~m}^{-2}$ similar to van der Waals energy between graphite layers [21]. Thereby, they enhance the stability and exfoliation of the prepared graphene-containing dispersion.

Low-boiling solvents such as water $\left(72 \mathrm{~mJ} \mathrm{~m}^{-2}\right)$ and ethanol $\left(22 \mathrm{~mJ} \mathrm{~m}^{-2}\right)$ are known to be unsuitable for the direct exfoliation of graphene [24]. In contrast, highly polar solvents with high boiling points have been utilized for graphene exfoliation, including $\mathrm{N}, \mathrm{N}-$ dimethylformamide (DMF) [25-27], N-methylpyrrolidone (NMP) [28-30], N,Ndimethylacetamide (DMAC) [28], $\gamma$-butyrolactone (GBL) [28], and Dimethylsulfoxide (DMSO) [31, 32]. The surface tensions of them are around $40 \mathrm{~mJ} \mathrm{~m}^{-2}$ [21]. In general, aminebased solvents such as DMF and NMP were used to produce high-quality and oxygen-free graphene nanosheets [21, 25]. Nonpolar solvents such as ortho-dichlorobenzene (ODCB) were also reported to produce homogeneous graphene dispersion [33, 34]. ODCB is an aromatic solvent with a high boiling point and surface tension of $36.6 \mathrm{~mJ} . \mathrm{m}^{-2}$. In ODCB, the singlewalled nanotube dispersion is stable presumably via efficient $\pi-\pi$ interactions [35]. However, other aromatic solvents such as benzene, toluene, xylene, and chlorobenzene were not successful in graphene exfoliation [36]. LPE of graphene has been extensively studied experimentally, but the choice of solvent was mainly based on the criterion of surface tension. Unfortunately, many solvents with appropriate surface tensions, such as pyridine $\left(38 \mathrm{~mJ} \mathrm{~m}^{-2}\right)$ and ethylene glycol $\left(47 \mathrm{~mJ} \mathrm{~m}^{-2}\right)$, do not work. Certainly, the molecular level information of interactions between solvent and graphene, closely related to exfoliation, can be extracted from quantum calculations and molecular dynamics (MD) [37-40]. However, useful criteria for determining suitable solvent for graphene exfoliation have not been reported until now, to the best of our knowledge.

MD simulations and quantum calculations have been used to study the interactions between parallel graphene sheets and various polar or nonpolar solvents at the molecular level. The potential of mean force between two parallel graphene sheets was calculated by MD for popular polar solvents: water, NMP, DMF, DMSO, and GBL [37]. The ranking of the five solvents: $\mathrm{NMP} \approx \mathrm{DMSO}>\mathrm{DMF}>\mathrm{GBL}>$ water, corresponds to the thermodynamic stability of the unfunctionalized graphene dispersion. The weak interactions between alcohols and graphene sheets calculated by the density gradient method indicated that alcohols with more carbon atoms could be a starting point for selecting a suitable solvent for graphene dispersion. [38]. The adsorption of methylbenzene on graphene acquired by the density functional theory (DFT) revealed that the adsorption energy increases approximately linearly with the number of methyl groups in the molecule [39]. Also, adsorption of chlorobenzenes (CBs) has been investigated by DFT, showing that the attraction between $\mathrm{CBs}$ and graphene grows with increasing the chlorine content [40].

This paper reports MD simulations based on the interaction between a single graphene sheet and the chosen polar and nonpolar solvents. A simple thermodynamics model has been proposed to show that solvation energy indicates the effective solvent for spontaneous exfoliation. MD simulations were used to calculate the solvation energies of twelve different organic solvents surrounding the graphene sheet. The density distribution of solvent molecules near the graphene surface was determined. The established model can be used to determine the solvent quality for other solvents in graphene exfoliation. 


\section{Materials and Methods}

The MD simulations were carried out with NAMD [41] (version 2.13), and the geometry optimizations for all organic molecules were carried out by Gaussian 09 package [42]. The TIP3P model for water has been used in our simulations [43]. All force-field parameters of organic solvents were acquired from the LigParGen server [44-46]. They are based on optimized potentials for liquid simulations-all atoms (OPLS-AA) force-fields combined with partial charges, which were obtained from quantum calculations using the B3LYP/6-311++G** basis sets with the Gaussian 09 software package. The force-field parameters of all carbon atoms in graphene were acquired from the reported values [47, 48], and there is no partial charge on each carbon atom. The van der Waals (vdW) attractions and steric repulsions between different atoms were represented by Lennard-Jones potential [49]. The atom-based cutoff is $12 \AA$ in vdW interactions. The particle-mesh Ewald summation method was used to compute the long-range electrostatic interactions [50, 51].

The MD simulations were performed at close to standard conditions for temperature and pressure ( $300 \mathrm{~K}$ and 1 bar). The square graphene sheet with the size $35 \times 35 \AA^{2}$ was immersed in the organic solvent within a cubic box with $65 \times 65 \times 65 \AA^{3}$, as shown in Figure 1. Initially, the systems were subjected to a series of pre-processing stages, first 10,000 steps of energy minimization were performed, and then each of the systems was gradually heated from 0 to $300 \mathrm{~K}$ using temperature-reassigning parameters of NAMD. Thereafter, the systems were pre-equilibrated up to $2 \mathrm{~ns}$ in the NPT ensemble. Equilibrium properties were calculated after $10 \mathrm{~ns}$ long production runs. The pressure and temperature were controlled by the Langevin piston and thermostat, respectively. The Verlet algorithm was used to integrate the equations of motion with a time step of $1 \mathrm{fs}$. Periodic boundary conditions were applied in all three directions. The surface tension of solvents has been calculated using the pressure tensor method [52]. It depends on the components of the pressure tensor and their normal and tangential components.

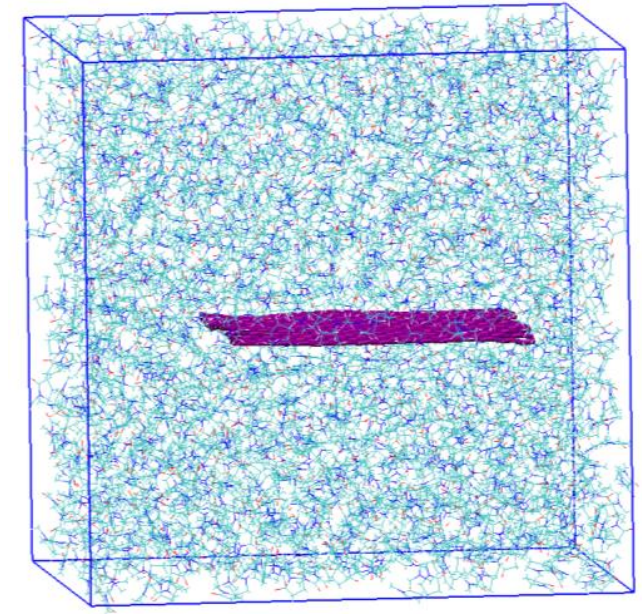

Figure 1. Snapshot of a single-layer graphene sheet immersed in an organic solvent.

The solvation energies of a single graphene sheet in solvents were calculated by the following equation [53].

$$
\Delta \boldsymbol{E}_{\text {sol }}=\Delta \boldsymbol{E}_{\text {cav }}+\Delta \boldsymbol{E}_{e l}+\Delta \boldsymbol{E}_{\text {sr }}
$$


where $\Delta \boldsymbol{E}_{\boldsymbol{c} \boldsymbol{c} \boldsymbol{v}}$ is the energy for the creation of the excluded volume for the solvent around the graphene sheet. $\Delta \boldsymbol{E}_{\boldsymbol{e l}}$ and $\Delta \boldsymbol{E}_{\boldsymbol{s} r}$ are the energies of the electrostatic interactions and van der Waals -like interactions between graphene and solvents. The electrostatic interactions between a graphene sheet and all the solvents are zero since the atoms of the graphene sheet have zero charge. The graphene-graphene attraction energies were calculated by the van der Waals (vdW) attractive interactions between the graphene sheets [37].

\section{Results and Discussion}

\subsection{Single graphene sheet in water, $n$-hexane, benzene, and ethanol.}

It is well known that graphene sheets are not stable in water, and they tend to stick together because of their hydrophobicity [54]. Moreover, the single sheet is always flat without perceptible deformation subject to thermal fluctuations. The hydrophobicity of graphene can be demonstrated from the density profile of water in the vicinity of the sheet. As shown in Figure $2 \mathrm{a}$, the water density near the sheet $(\mathrm{z}=0 \sim 5 \AA)$ is much less than that in bulk. An undeformed graphene sheet in water can be studied by estimating the probability distribution of its $\mathrm{C}-\mathrm{C}$ bond lengths, as depicted in Figure $2 \mathrm{~b}$. The mean value of the bond length is 1.408 $\AA$, which is essentially the same as the literature value in a vacuum (1.410 $\mathrm{A})$. Similarly, the standard deviation is $0.072 \AA$ in water and almost the same as that in vacuum $(0.070 \AA)$, revealing a very slight influence of solvent on bond fluctuations.
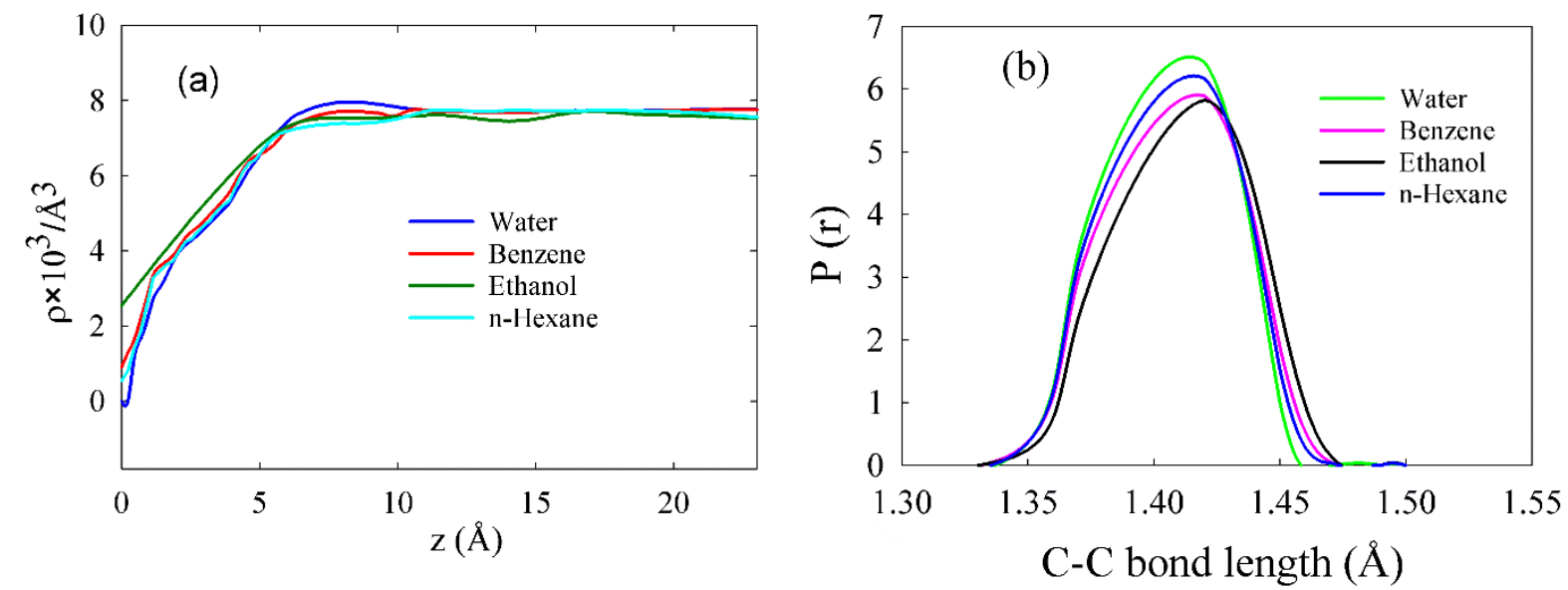

Figure 2. (a) The number density profiles $(\rho)$ of water, benzene, ethanol, and n-Hexane from the graphene surface; (b) The probability distribution of C-C bond lengths for a single graphene sheet in water, benzene, ethanol, and n-Hexane.

In order to realize the thermodynamics of exfoliation, the solvation enthalpy of a graphene sheet in water has been calculated, $\mathrm{E}_{\text {sol }}$ (water) $=2.46 \mathrm{~mJ} \mathrm{~m}^{-2}$, based on the interaction energy between a single graphene sheet and all surrounding solvent molecules. To make a comparison, the interaction energy between two graphene sheets per unit area is determined as well, $\mathrm{E}_{\mathrm{g}-\mathrm{g}}$ (water) $=-92.9 \mathrm{~mJ} \mathrm{~m}^{-2}$ in water. It is also found that the $E_{g-g}$ (water) is slightly different from that in vacuum $E_{g-g}$ (vacuum) $=-94.2 \mathrm{~mJ} \mathrm{~m}^{-2}$. The difference between them may be attributed to the slight distortion of the two-layer graphene sheets in water. N-Hexane, benzene, and ethanol have been used as solvents for exfoliation, but their efficiencies are very poor [24, 36, 55]. Based on the analysis for water, their exfoliation efficiency can be examined. The density profiles of n-hexane, benzene, and ethanol near the graphene sheet are also shown in Figure 2a. Their distributions are similar to that of water, revealing the dislike of graphene for them. Nonetheless, both of them are able to induce a 
slightly more deformation of a single graphene sheet as compared to water. The extent of graphene deformation can be realized from Figure $2 \mathrm{~b}$ for the distribution of $\mathrm{C}-\mathrm{C}$ bond lengths. The mean values of the bond length in n-hexane, benzene, and ethanol are 1.409, 1.410, and $1.416 \AA$, respectively. The standard deviations are $0.121,0.135$, and $0.145 \AA$, respectively. Those results indicate that their interactions with graphene are similar to water and the graphene deformation is not significant. Moreover, the solvation energy of a graphene sheet in n-hexane, benzene, and ethanol have been evaluated, $E_{\text {sol }}(n-$ hexane $)=-1.52 \mathrm{~mJ} \mathrm{~m}^{-2}$, $\mathrm{E}_{\mathrm{sol}}$ (benzene) $=-18.83 \mathrm{~mJ} \mathrm{~m}^{-2}$, and $\mathrm{E}_{\mathrm{sol}}($ ethanol $)=-22.01 \mathrm{~mJ} \mathrm{~m}^{-2}$. The solvation energy of them is significantly higher than the graphene-graphene attraction $\mathrm{E}_{\mathrm{g}-\mathrm{g}},\left(-94.2 \mathrm{~mJ} \mathrm{~m}^{-2}\right)$. It indicates that water, $\mathrm{n}$-hexane, ethanol, and benzene are expected to be poor choices for LPE.

\subsection{Single graphene sheet in the good quality solvent.}

It has been reported that the common organic solvents, including NMP, DMSO, DMF, and ODCB are well-known good solvents for LPE of graphene [17, 37]. The surface tensions of NMP, DMSO, DMF, and ODCB are 38.2, 41.7, 39.1, and $35.5 \mathrm{~mJ} \mathrm{~m}-2$, respectively, which lead to better stability of exfoliated graphene. The surface tension of the six organic solvents has been reported in Table 1. The range of solvent surface tension that can be used to exfoliate graphene is $35-50 \mathrm{~mJ} \mathrm{~m}-2$. The solvent density profile is acquired near the graphene sheet and solvation energy to examine their solvent quality for spontaneous exfoliation. Figure $3 \mathrm{a}$ illustrates the distributions $\rho(\mathrm{z})$ for the six solvents, and their behaviors are distinctly different from those of water, benzene, ethanol shown in Figure 2a. The density of NMP, DMSO, DMF, and ODCB close to the sheet is higher than that in bulk $\rho b$, indicating the solvophilic tendency of graphene. Moreover, the densities of NMP and DMSO near the sheet are higher than that of the other solvents, revealing that more NMP and DMSO molecules are adsorbed on the graphene surface. The graphene sheet deformation can be realized from Figure $3 \mathrm{~b}$ for the distribution of C-C bond lengths. The sheet deformation in terms of the mean bond length is significantly higher in these organic solvents than in water. The mean bond length in NMP, DMSO, DMF, ODCB, DMAC, and GBL is $1.439,1.435,1.433,1.429,1.427$, and $1.425 \AA$, respectively. The standard deviations are $0.327,0.318,0.272,0.216,0.208$, and $0.202 \AA$, respectively. The solvation energy of a single graphene sheet in NMP, DMSO, DMF, ODCB, DMAC, and GBL is obtained as well, $\mathrm{E}_{\mathrm{sol}}(\mathrm{NMP})=-177.37 \mathrm{~mJ} \mathrm{~m}^{-2}, \quad \mathrm{E}_{\mathrm{sol}}(\mathrm{DMSO})=$ $-172.13 \mathrm{~mJ} \mathrm{~m}^{-2}, \quad \mathrm{E}_{\text {sol }}(\mathrm{DMF})=-153.44 \mathrm{~mJ} \mathrm{~m}^{-2}, \quad \mathrm{E}_{\text {sol }}(\mathrm{ODCB})=-134.64 \mathrm{~mJ} \mathrm{~m}^{-2}$, $E_{\text {sol }}(D M A C)=-126.54 \mathrm{~mJ} \mathrm{~m}^{-2}$, and $E_{\text {sol }}(G B L)=-108.52 \mathrm{~mJ} \mathrm{~m}^{-2}$. The fact that the solvation energy of them is significantly less than the graphene-graphene attraction $\mathrm{E}_{\mathrm{g}-\mathrm{g}}$ explains their successful exfoliation of graphene observed in experiments. The solvation energy is found to be strongly correlated to the number density profile of the solvents from the graphene surface and sheet deformation, and these properties can be used to predict the solvent quality for LPE: NMP>DMSO>DMF>ODCB $>$ DMAC $>$ GBL .

\subsection{Comparing LPE in Amine, sulfoxide, and halogen-benzene-based organic solvents.}

The organic amine-based solvents NMP, DMF, and DMAC have been proved to be good solvents for the exfoliation of graphene in previous experimental studies [21]. The orientation and structural changes of various organic solvents on graphene are studied by MD simulations. 
Table 1. Surface tensions $\left(\mathrm{mJ} \mathrm{m}^{-2}\right)$ and solvation energy $\left(\mathrm{mJ} \mathrm{m}^{-2}\right)$ of the various organic solvents were calculated at $300 \mathrm{~K}$.

\begin{tabular}{|c|c|c|c|c|c|}
\hline \multirow[t]{2}{*}{ Type } & \multirow[t]{2}{*}{ Organic Solvents } & \multirow[t]{2}{*}{$\begin{array}{l}\text { Optimization } \\
\text { Structure }\end{array}$} & \multirow{2}{*}{$\begin{array}{c}\text { Solvation } \\
\text { Energy } \mathbf{m J} \\
\mathbf{m}^{-2}\end{array}$} & \multicolumn{2}{|c|}{$\begin{array}{c}\text { Surface Tension } \\
\mathrm{mJ} \mathrm{m}^{-2}\end{array}$} \\
\hline & & & & MD & Literature $^{11}$ \\
\hline Amine group & $\begin{array}{l}\text { N-methyl-2-pyrrolidone } \\
\text { (NMP) }\end{array}$ & & -177.37 & $38.2 \pm 0.21$ & 40.0 \\
\hline & $\begin{array}{l}\mathrm{N}, \mathrm{N} \text {-dimethylformamide } \\
\text { (DMF) }\end{array}$ & & -153.44 & $39.1 \pm 0.33$ & 37.1 \\
\hline & $\begin{array}{l}\text { N,N-dimethylacetamide } \\
\text { (DMAC) }\end{array}$ & & -126.54 & $37.4 \pm 0.24$ & 36.7 \\
\hline $\begin{array}{l}\text { Sulfoxide } \\
\text { group }\end{array}$ & $\begin{array}{l}\text { Dimethylsulfoxide } \\
\text { (DMSO) }\end{array}$ & & -172.13 & $41.7 \pm 0.27$ & 42.9 \\
\hline $\begin{array}{l}\text { Halogen- } \\
\text { benzene }\end{array}$ & $\begin{array}{l}\text { ortho-Dichlorobenzene } \\
\text { (ODCB) }\end{array}$ & & -134.647 & $35.5 \pm 0.31$ & 37.0 \\
\hline Lactone & $\begin{array}{c}\text { gamma-Butyrolactone } \\
\text { (GBL) }\end{array}$ & & -108.527 & $47.2 \pm 0.36$ & 46.5 \\
\hline
\end{tabular}
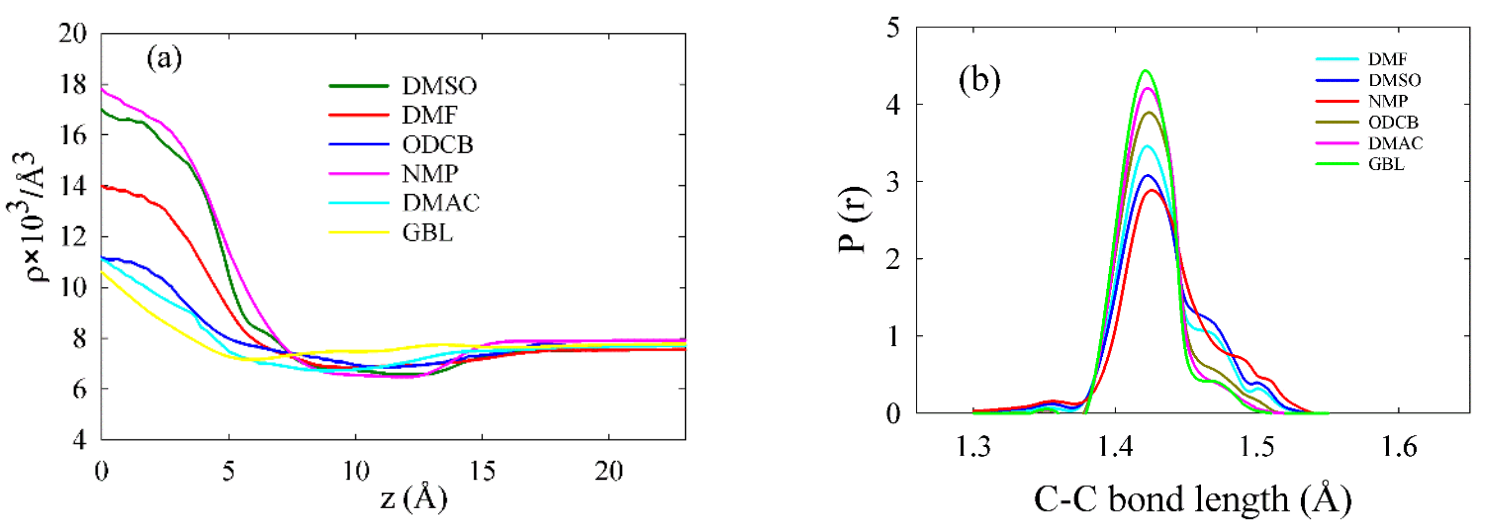

Figure 3. (a) The number density profiles $(\rho)$ of NMP, DMSO, DMF, ODCB, DMAC, and GBL from the graphene surface (b) The probability distribution of C-C bond lengths for a single graphene sheet in pure NMP, DMSO, DMF, ODCB, DMAC, and GBL.

In Figure 4, the orientation and positions of the solvent molecules near the graphene surface are indicated. The NMP molecules can also lie plane of the graphene surface when they are placed parallel to the surface. In the first adsorption layer, the NMP molecules are placed parallel to the graphene surface at a distance of $3.14 \AA$, whereas the DMF and DMAC are oriented at a distance of 3.25 and $3.42 \AA$, respectively from the surface of graphene.

On the other hand, DMSO and GBL show the tilt angle of adsorbed solvents at a distance of 3.21 and $3.56 \AA$, respectively. In the case of ODCB solvent, some molecules 
arranged parallel to the graphene surface at an average distance of $3.34 \AA$. Currently, no experimental data is available regarding the molecular orientation of certain solvent molecules near the graphene surface. The aforementioned analyses indicate the strong correlation between solvation energy and solvent-graphene distance.

(a)

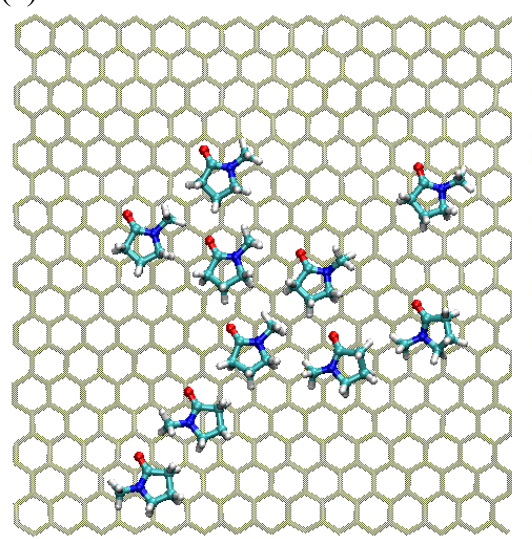

(d)

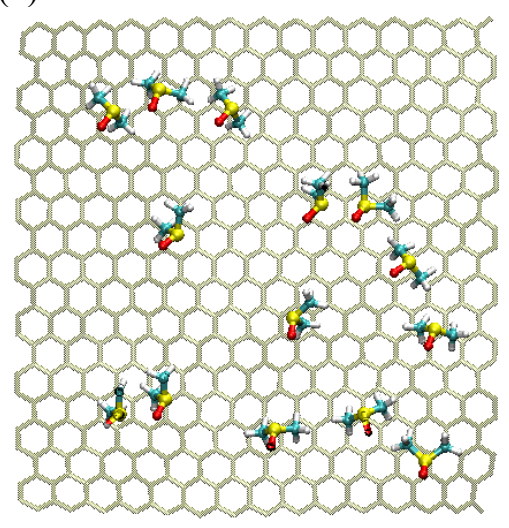

(b)

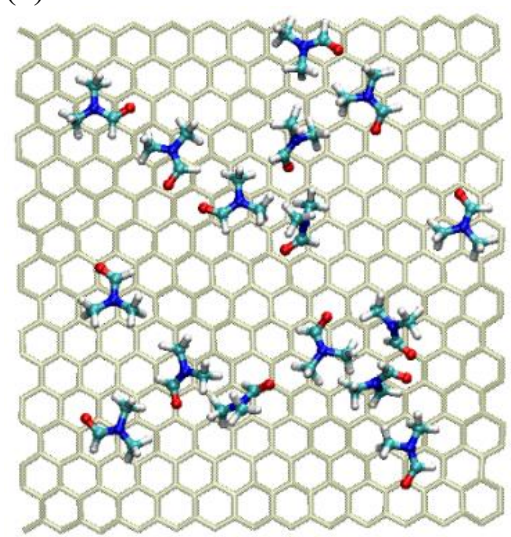

(e)

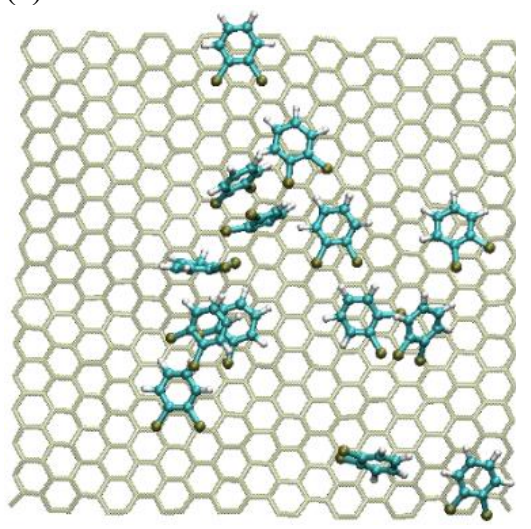

(c)

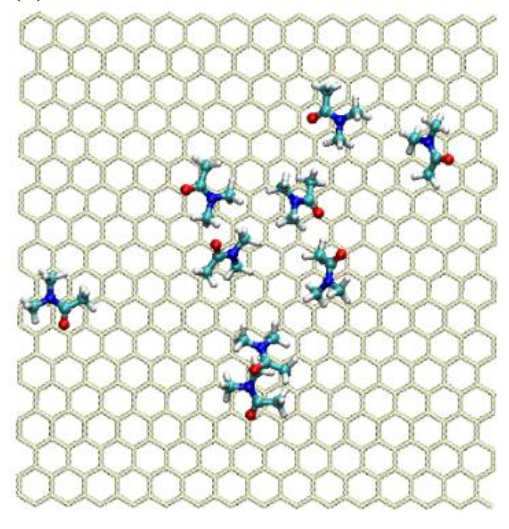

(f)

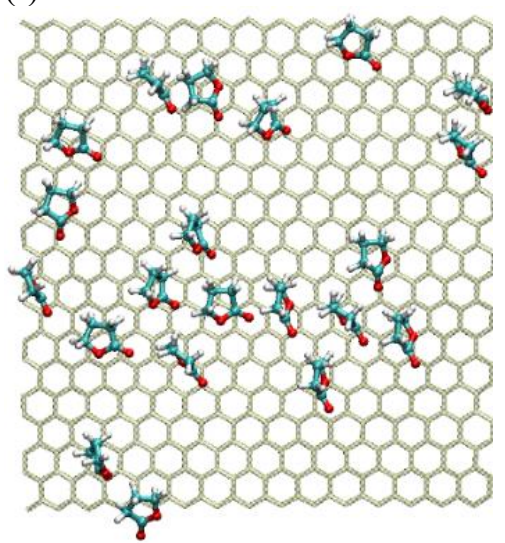

Figure. 4 Snapshots of the orientation and relative positions of the (a) NMP, (b) DMF, (c) DMAC, (d) DMSO, (e) ODCB, and (f) GBL on the graphene surface.

Table 2. The solvation energies $\left(\mathrm{mJ} \mathrm{m}^{-2}\right)$ of a single graphene sheet in different solvents, solvent-graphene distance $(\AA)$ and surface excess $\left(\times 10^{-3} \AA^{-2}\right)$ calculated at $300 \mathrm{~K}$.

\begin{tabular}{l|c|c|c} 
Solvents & $\boldsymbol{E}_{\text {sol }}\left(\mathbf{m} \mathbf{J ~ m}^{-\mathbf{2}}\right)$ & $\begin{array}{c}\text { solvent-graphene } \\
\text { distance }(\AA)\end{array}$ & surface excess $\left(\times \mathbf{1 0}^{-\mathbf{3}} \AA^{-\mathbf{2}}\right)$ \\
\hline Water & 2.46 & 4.15 & -0.42 \\
\hline n-Hexane & -1.52 & 4.12 & -0.41 \\
\hline Benzene & -18.83 & 4.08 & -0.40 \\
\hline Acetone & -20.33 & 3.94 & -0.38 \\
\hline Ethanol & -22.01 & 3.86 & -0.37 \\
\hline Pyridine & -22.28 & 3.77 & -0.36 \\
\hline Xylene & -23.38 & 3.72 & -0.35 \\
\hline GBL & -108.52 & 3.56 & 0.01 \\
\hline DMAC & -126.54 & 3.42 & 0.02 \\
\hline ODCB & -134.64 & 3.34 & 0.03 \\
\hline DMF & -153.44 & 3.25 & 0.14 \\
\hline DMSO & -172.13 & 3.21 & 0.29 \\
\hline NMP & -177.37 & 3.14 & 0.36
\end{tabular}

Figure 5 shows the variation of the solvation energy with the length of the C-C bond. It has been found that the magnitude of the solvation energy $\left(\left|E_{\text {sol }}\right|\right)$ generally increases as the deformation of the graphene sheet increases. It can be attributed to the reason that the attractive interactions between the solvent molecules and the graphene sheet tend to enlarge their contact area by warping the planar sheet. According to DMSO and ODCB in Figure 5, sulfoxide-based and halogen-benzene-based organic solvents are promising as good solvents for spontaneous 
exfoliation. The sheet deformation in terms of the mean bond length is higher in NMP and DMSO compared to other solvents. The values of the solvation energies $\left(\mathrm{E}_{\mathrm{sol}}\right)$ for single graphene sheet in organic solvents and the solvent-graphene distance are given in Table 2 . The solvation energy is strongly correlated with the solvent-graphene distance. From Table 2, it is observed that the magnitude of the solvation energy $\left(\left|\mathrm{E}_{\text {sol }}\right|\right)$ grows in general as the solventgraphene distance is getting smaller. The solvent-graphene distance is lower for NMP $(3.14 \AA)$ and DMSO (3.21 $\AA$ ) compared to others. By comparing the solvation energy, the sulfoxidebased solvents are generally better than the halogen-benzene-based solvents.

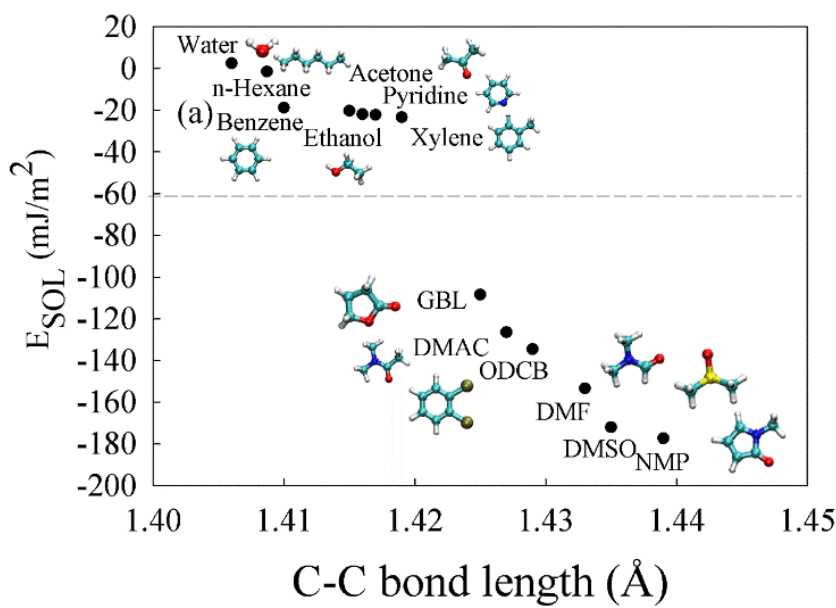

Figure 5. The solvation energy of a single graphene sheet in various solvents as a function of C-C bond length.

In addition to solvation energy, the density distribution of solvent molecules near the graphene sheet $\rho(\mathrm{z})$ is also an indication of spontaneous exfoliation. The density profiles for organic solvents near the graphene sheet have been shown in Figures $2 \mathrm{a}$ and $3 \mathrm{a}$. The adsorption profile is measured by the surface excess $\Gamma$ which is defined as $\Gamma=\int_{-\infty}^{\infty}\left(\rho(z)-\rho_{b}\right) d z,[56]$ where $\rho_{b}$ is the bulk concentration. The positive value of $\Gamma$ specifies the accumulation of solvent at the graphene surface, whereas the negative value indicates depletion compared to the bulk concentration. From Table 2, it is found that the surface excess is strongly correlated with the solvation energy. As anticipated, the larger the surface excess, the greater the magnitude of the solvation energy $\left(\left|\mathrm{E}_{\mathrm{sol}}\right|\right)$. Moreover, the descending order of solvation quality is the same as the surface excess for all compounds studied. In accordance with Figure 5 and Table 2, the solvent with the best solvation ability for graphene shows significant structural deformation, high solvation energy, and large surface excess.

The single graphene sheet is predicted to exfoliate in different organic solvents on the basis of thermodynamic arguments. Four types of solvents for spontaneous exfoliation are identified. The magnitudes of their solvation energy are high and can be realized from their attractive interactions with graphene. Specifically, according to the solvation energy, this is due to the fact that the enormous vdW and electrostatic interactions between the graphene sheet and solvents are responsible for the higher magnitude of solvation energy. It was found that the magnitude of the solvation energy increases with a decrease in solvent-graphene distance. Moreover, the NMP-NMP interaction energy has been calculated, $\mathrm{E}_{\mathrm{NMP}-\mathrm{NMP}}=$ $-98.14 \mathrm{~mJ} \mathrm{~m}^{-2}$. The solvation energy of a single graphene sheet in NMP $\left(-177.37 \mathrm{~mJ} \mathrm{~m}^{-2}\right)$ is significantly higher than the NMP-NMP attraction explains the successful exfoliation of graphene observed in NMP solvent. It should be noted that simulations of exfoliation of a threelayer graphene sheet have been performed. The three-layer graphene sheet (area = 36 $\times 36 \AA^{2}$ ) 
was immersed in an $80 \times 80 \times 80 \AA^{3} \mathrm{NMP}$ and water box, as shown in Figure 6 . Initial configurations were created by placing the three parallel graphene sheets with the same spacing between the sheets and then filling the simulation box with a sufficient number of NMP and water molecules. The interaction between three parallel graphene sheets requires 2 ns to reach equilibrium. The simulated systems were equilibrated for $10 \mathrm{~ns}$. Spontaneous exfoliation can be clearly observed for NMP after about $20 \mathrm{~ns}$, but the three-layer sheet remains stacked for water, consistent with our solvation criterion.

(a)
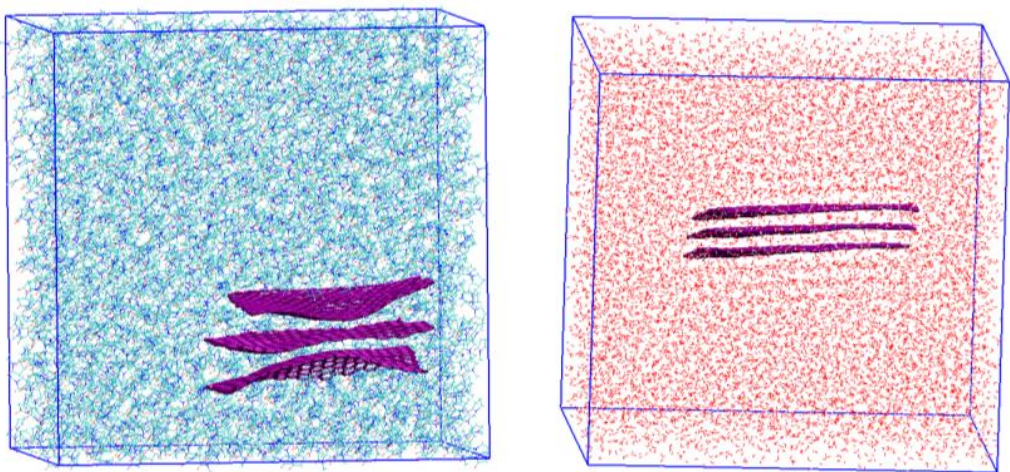

(b)

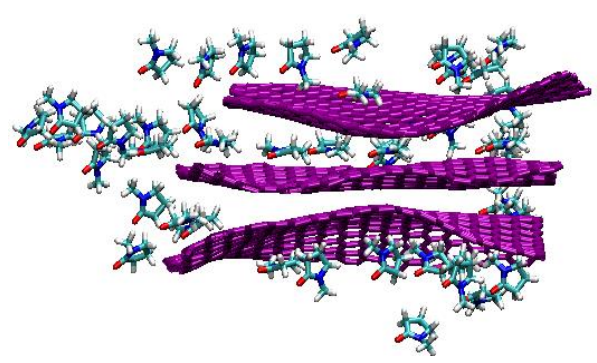

(c)

Figure 6. The snapshots of the (a) exfoliated three-layer sheet in NMP; (b) stacked three-layer sheet in water; (c) side view of NMP molecules between graphene sheets.

\section{Conclusions}

Polar and nonpolar solvents were studied for the liquid phase exfoliation of graphene. The main criteria for choosing a solvent were the solvation energy related to the $\mathrm{C}-\mathrm{C}$ bond length and the distance between the solvent molecule and graphene. In addition, the surface excess relates closely to the solvation energy, and the positive surface excess is an indication of an efficient solvent. NMP was identified as a good solvent for achieving this objective. The descending ranking of the solvation quality of common solvents is $\mathrm{NMP}>\mathrm{DMSO}>\mathrm{DMF}>\mathrm{ODCB}>\mathrm{DMAC}>\mathrm{GBL}$. Four types of good solvents are identified for spontaneous exfoliation: amine-, sulfoxide-, halogen-benzene-based, and cyclic ether and lactone solvents.

\section{Funding}

This research received no external funding.

\section{Acknowledgments}

Vellore Institute of Technology is gratefully acknowledged for providing high-performance computing technology for this work. 


\section{Conflicts of Interest}

\section{The author declares no conflict of interest.}

\section{References}

1. de Oliveira, C.R.; Rocha, V.L. Dirac cones for bi-and trilayer Bernal-stacked graphene in a quantum graph model. J. Phys. A Math. Theor. 2020, 53, 505201, https://doi.org/10.1088/1751-8121/abc6c1.

2. Kozioł, Z. Number of equidistant neighbors on honeycomb lattice. J. Phys. Commun. 2020, 4, 075003, https://doi.org/10.1088/2399-6528/aba035.

3. Muraru, S.; Burns, J.S.; Ionita, M. GOPY: A tool for building 2D graphene-based computational models. SoftwareX 2020, 12, 100586, https://doi.org/10.1016/j.softx.2020.100586.

4. de Oliveira, C.R.; Rocha, V.L. Dirac cones for graph models of multilayer AA-stacked graphene sheets. Zeitschrift für Naturforschung A 2021, 76, 371-384, https://doi.org/10.1515/zna-2020-0330.

5. Palermo, V. Not a molecule, not a polymer, not a substrate... the many faces of graphene as a chemical platform. ChemComm. 2013, 49, 2848-2857, https://doi.org/10.1039/C3CC37474B.

6. Denis, P.A. Chemical reactivity of electron-doped and hole-doped graphene. The J. Phys. Chem. C 2013, 117, 3895-3902, https://doi.org/10.1021/jp306544m.

7. Denis, P.A.; Iribarne, F. [2+ 2] Cycloadditions onto graphene. J. Mater. Chem. 2012, 22, 5470-5477, https://doi.org/10.1039/C2JM15454D.

8. Güler, Ö.; Bağc1, N. A short review on mechanical properties of graphene reinforced metal matrix composites. J. Mater. Res. Technol. 2020, 9, 6808-6833, https://doi.org/10.1016/j.jmrt.2020.01.077.

9. Kumar, A.; Sharma, K.; Dixit, A.R. Carbon nanotube-and graphene-reinforced multiphase polymeric composites: review on their properties and applications. J. Mater. Sci. 2020, 55, 2682-2724, https://doi.org/10.1007/s10853-019-04196-y.

10. Kumar, N.; Salehiyan, R.; Chauke, V.; Botlhoko, O.J.; Setshedi, K.; Scriba, M.; Masukume, M.; Ray, S.S. Top-down synthesis of graphene: A comprehensive review. FlatChem 2021, 27, 100224, https://doi.org/10.1016/j.flatc.2021.100224.

11. Jacobse, P.H.; McCurdy, R.D.; Jiang, J.; Rizzo, D.J.; Veber, G.; Butler, P.; Zuzak, R.; Louie, S.G.; Fischer, F.R.; Crommie, M.F. Bottom-up assembly of nanoporous graphene with emergent electronic states. J. Am. Chem. Soc. 2020, 142, 13507-13514, https://doi.org/10.1021/jacs.0c05235.

12. Hernandez, Y.; Nicolosi, V.; Lotya, M.; Blighe, F.M.; Sun, Z.; De, S.; McGovern, I.; Holland, B.; Byrne, M.; Gun'Ko, Y.K. High-yield production of graphene by liquid-phase exfoliation of graphite. Nat. Nanotechnol. 2008, 3, 563-568, https://doi.org/10.1038/nnano.2008.215.

13. Shen, Z.; Li, J.; Yi, M.; Zhang, X.; Ma, S. Preparation of graphene by jet cavitation. Nanotechnology 2011, 22, 365306, https://doi.org/10.1088/0957-4484/22/36/365306.

14. Paton, K.R.; Varrla, E.; Backes, C.; Smith, R.J.; Khan, U.; O'Neill, A.; Boland, C.; Lotya, M.; Istrate, O.M.; King, P. Scalable production of large quantities of defect-free few-layer graphene by shear exfoliation in liquids. Nat. Mater. 2014, 13, 624-630, https://doi.org/10.1038/nmat3944.

15. Amri, A.; Hendri, Y.B.; Yin, C.-Y.; Rahman, M.M.; Altarawneh, M.; Jiang, Z.-T. Very-few-layer graphene obtained from facile two-step shear exfoliation in aqueous solution. Chem. Eng. Sci. 2021, 245, 116848, https://doi.org/10.1016/j.ces.2021.116848.

16. Bayazit, M.K.; Xiong, L.; Jiang, C.; Moniz, S.J.; White, E.; Shaffer, M.S.; Tang, J. Defect-Free Single-Layer Graphene by $10 \mathrm{~s}$ Microwave Solid Exfoliation and Its Application for Catalytic Water Splitting. ACS Appl. Mater. Interfaces 2021, 13 , 28600-28609, https://doi.org/10.1021/acsami.1c03906.

17. Du, W.; Lu, J.; Sun, P.; Zhu, Y.;Jiang, X. Organic salt-assisted liquid-phase exfoliation of graphite to produce high-quality graphene. Chem. Phys. Lett. 2013, 568, 198-201, https://doi.org/10.1016/j.cplett.2013.03.060.

18. Tang, H.; Liu, D.; Zhao, Y.; Yang, X.; Lu, J.; Cui, F. Molecular dynamics study of the aggregation process of graphene oxide in water. J. Phys. Chem. C 2015, 119, 26712-26718, https://doi.org/10.1021/acs.jpcc.5b07345.

19. Li, L.-s.; Yan, X. Colloidal graphene quantum dots. J. Phys. Chem. Lett. 2010, 1, 2572-2576, https://doi.org/10.1021/jz100862f.

20. O'Neill, A.; Khan, U.; Nirmalraj, P.N.; Boland, J.; Coleman, J.N. Graphene dispersion and exfoliation in low boiling point solvents. J. Phys. Chem. C 2011, 115, 5422-5428, https://doi.org/10.1021/jp110942e.

21. Xu, Y.; Cao, H.; Xue, Y.; Li, B.; Cai, W. Liquid-Phase exfoliation of graphene: An overview on exfoliation media, techniques, and challenges. Nanomaterials 2018, 8, 942, https://doi.org/10.3390/nano8110942.

22. Ton, N.N.T.; Ha, M.-Q.; Ikenaga, T.; Thakur, A.; Dam, H.-C.; Taniike, T. Solvent screening for efficient chemical exfoliation of graphite. 2d Mater. 2020, 8, 015019, https://doi.org/10.1088/2053-1583/abc08a.

23. PA, S.; NM, S. One step synthesis of graphene. Inorg. Nano-Met. Chem. 2020, 50, 73-79, https://doi.org/10.1080/24701556.2019.1661470. 
24. Zhang, X.; Coleman, A.C.; Katsonis, N.; Browne, W.R.; Van Wees, B.J.; Feringa, B.L. Dispersion of graphene in ethanol using a simple solvent exchange method. ChemComm. 2010, 46, 7539-7541, https://doi.org/10.1039/C0CC02688C.

25. Coleman, J.N. Liquid exfoliation of defect-free graphene. Acc. Chem. Res. 2012, 46, 14-22, https://doi.org/10.1021/ar300009f.

26. Gomez, C.V.; Guevara, M.; Tene, T.; Villamagua, L.; Usca, G.T.; Maldonado, F.; Tapia, C.; Cataldo, A.; Bellucci, S.; Caputi, L.S. The liquid exfoliation of graphene in polar solvents. Appl. Surf. Sci. 2021, 546, 149046, https://doi.org/10.1016/j.apsusc.2021.149046.

27. Trusova, E.A.; Klimenko, I.V.; Afzal, A.M.; Shchegolikhin, A.N.; Jurina, L.V. Comparison of oxygen-free graphene sheets obtained in DMF and DMF-aqua media. New J Chem 2021, https://doi.org/10.1039/D1NJ01015H.

28. Hernandez, Y.; Nicolosi, V.; Lotya, M.; Blighe, F.M.; Sun, Z.; De, S.; McGovern, I.; Holland, B.; Byrne, M.; Gun'Ko, Y.K. High-yield production of graphene by liquid-phase exfoliation of graphite. Nat. Nanotechnol. 2008, 3, 563, https://doi.org/10.1038/nnano.2008.215.

29. Liang, B.; Liu, K.; Liu, P.; Qian, L.; Zhao, G.; Pan, W.; Chen, C. Organic salt-assisted liquid-phase shear exfoliation of expanded graphite into graphene nanosheets. J. Mater. 2021, 7, 1181-1189, https://doi.org/10.1016/j.jmat.2021.03.007.

30. Yan, Y.; Manickam, S.; Lester, E.; Wu, T.; Pang, C.H. Synthesis of graphene oxide and graphene quantum dots from miscanthus via ultrasound-assisted mechano-chemical cracking method. Ultrason Sonochem 2021, 73, 105519, https://doi.org/10.1016/j.ultsonch.2021.105519.

31. Blake, P.; Brimicombe, P.D.; Nair, R.R.; Booth, T.J.; Jiang, D.; Schedin, F.; Ponomarenko, L.A.; Morozov, S.V.; Gleeson, H.F.; Hill, E.W. Graphene-based liquid crystal device. Nano Lett. 2008, 8, 17041708, https://doi.org/10.1021/n1080649i.

32. Chaudhary, N.; Bansal, S.; Khanuja, M. Edge, confinement effects, and measurement of the number of layers of MoS 2 nanosheets by liquid-exfoliated method assisted by different solvents. Int. Nano Lett. 2021, 1-7, https://doi.org/10.1007/s40089-021-00337-X.

33. Niyogi, S.; Hamon, M.; Perea, D.; Kang, C.; Zhao, B.; Pal, S.; Wyant, A.; Itkis, M.; Haddon, R.J.T. Ultrasonic dispersions of single-walled carbon nanotubes. J. Phys. Chem. B 2003, 107, 8799-8804, https://doi.org/10.1021/jp034866d.

34. Güler, Ö.; Tekeli, M.; Taşkın, M.; Güler, S.H.; Yahia, I. The production of graphene by direct liquid phase exfoliation of graphite at moderate sonication power by using low boiling liquid media: The effect of liquid media on yield and optimization. Ceram. Int. 2021, 47, 521-533, https://doi.org/10.1016/j.ceramint.2020.08.159.

35. Bahr, J.; Yang, J.; Kosynkin, D.V.; Bronikowski, M.J., Smalley, R.E., Tour, J.M.," Functionalization of carbon nanotubes by electrochemical reduction of aryl diazonium salts: A bucky paper electrode". J. Am. Chem. Soc. 2001, 123, 6536-6542, https://doi.org/10.1021/ja010462s.

36. Sham, A.Y.; Notley, S.M. A review of fundamental properties and applications of polymer-graphene hybrid materials. Soft Matter 2013, 9, 6645-6653, https://doi.org/10.1039/C3SM00092C.

37. Shih, C.-J.; Lin, S.; Strano, M.S.; Blankschtein, D. Understanding the stabilization of liquid-phase-exfoliated graphene in polar solvents: molecular dynamics simulations and kinetic theory of colloid aggregation. J. Am. Chem. Soc. 2010, 132, 14638-14648, https://doi.org/10.1021/ja1064284.

38. Wang, H.; Chen, S.; Lu, S.; Xiang, Y. Theoretical investigation of the weak interaction between graphene and alcohol solvents. Chem. Phys. Lett. 2017, 676, 129-133, https://doi.org/10.1016/j.cplett.2017.03.047.

39. Borck, Ø.; Schröder, E. Methylbenzenes on graphene. Surf. Sci. 2017, 664, 162-167, https://doi.org/10.1016/j.susc.2017.06.012.

40. Balamurugan, K.; Subramanian, V. Adsorption of chlorobenzene onto $(5,5)$ armchair single-walled carbon nanotube and graphene sheet: toxicity versus adsorption strength. J. Phys. Chem. C 2013, 117, 21217-21227, https://doi.org/10.1021/jp403646h.

41. Kalé, L.; Skeel, R.; Bhandarkar, M.; Brunner, R.; Gursoy, A.; Krawetz, N.; Phillips, J.; Shinozaki, A.; Varadarajan, K.; Schulten, K. NAMD2: greater scalability for parallel molecular dynamics. J. Comput. Phys. 1999, 151, 283-312, https://doi.org/10.1006/jcph.1999.6201.

42. Frisch, M.; Trucks, G.; Schlegel, H.; Scuseria, G.; Robb, M.; Cheeseman, J.; Scalmani, G.; Barone, V.; Mennucci, B.; Petersson, G.; et al. Gaussian 09 package. Pittsburgh PA: Gaussian Inc 2009.

43. Jorgensen, W.L.; Chandrasekhar, J.; Madura, J.D.; Impey, R.W.; Klein, M.L. Comparison of simple potential functions for simulating liquid water. J. Chem. Phys. 1983, 79, 926-935, https://doi.org/10.1063/1.445869.

44. Jorgensen, W.L.; Tirado-Rives, J. Potential energy functions for atomic-level simulations of water and organic and biomolecular systems. Proc. Natl. Acad. Sci. 2005, 102, 6665-6670, https://doi.org/10.1073/pnas.0408037102.

45. Dodda, L.S.; Vilseck, J.Z.; Tirado-Rives, J.; Jorgensen, W.L. 1.14* CM1A-LBCC: localized bond-charge corrected CM1A charges for condensed-phase simulations. J. Phys. Chem. B 2017, 121, 3864-3870, https://doi.org/10.1021/acs.jpcb.7b00272. 
46. Dodda, L.S.; Cabeza de Vaca, I.; Tirado-Rives, J.; Jorgensen, W.L. LigParGen web server: an automatic OPLS-AA parameter generator for organic ligands. Nucleic Acids Res. 2017, 45, W331-W336, https://doi.org/10.1093/nar/gkx312.

47. Chaban, V.V.; Fileti, E.E. Graphene exfoliation in ionic liquids: unified methodology. RSC Adv. 2015, 5, 81229-81234, https://doi.org/10.1039/C5RA16857K.

48. Patra, N.; Wang, B.; Král, P. Nanodroplet activated and guided folding of graphene nanostructures. Nano Lett. 2009, 9, 3766-3771, https://doi.org/10.1021/nl9019616.

49. Ang, P.K.; Wang, S.; Bao, Q.; Thong, J.T.; Loh, K.P. High-throughput synthesis of graphene by intercalation- exfoliation of graphite oxide and study of ionic screening in graphene transistor. Acs Nano 2009, 3, 3587-3594, https://doi.org/10.1021/nn901111s.

50. Darden, T.; York, D.; Pedersen, L. Particle mesh Ewald: An N. log (N) method for Ewald sums in large systems. J. Chem. Phys. 1993, 98, 10089-10092, https://doi.org/10.1063/1.464397.

51. Essmann, U.; Perera, L.; Berkowitz, M.L.; Darden, T.; Lee, H.; Pedersen, L.G. A smooth particle mesh Ewald method. J. Chem. Phys. 1995, 103, 8577-8593, https://doi.org/10.1063/1.470117.

52. Biswas, R.; Ghosh, P.; Banerjee, T.; Ali, S.M.; Shenoy, K. Extractive insights in the cesium ion partitioning with bis (2-propyloxy)-calix [4] crown-6 and dicyclohexano-18-crown-6 in ionic liquid-water biphasic systems. J. Mol. Liq. 2017, 241, 279-291, https://doi.org/10.1016/j.molliq.2017.06.015.

53. Gonçalves, P.F.; Stassen, H. Calculation of the free energy of solvation from molecular dynamics simulations. Pure Appl. Chem. 2004, 76, 231-240, https://doi.org/10.1351/pac200476010231.

54. He, P.; Zhou, C.; Tian, S.; Sun, J.; Yang, S.; Ding, G.; Xie, X.; Jiang, M. Urea-assisted aqueous exfoliation of graphite for obtaining high-quality graphene. ChemComm. 2015, 51, 4651-4654, https://doi.org/10.1039/C5CC00059A.

55. Konios, D.; Stylianakis, M.M.; Stratakis, E.; Kymakis, E. Dispersion behaviour of graphene oxide and reduced graphene oxide. J. Colloid Interface Sci. 2014, 430, 108-112, https://doi.org/10.1016/j.jcis.2014.05.033.

56. Andersson, G.; Krebs, T.; Morgner, H. Activity of surface active substances determined from their surface excess. Phys. Chem. Chem. Phys. 2005, 7, 136-142, https://doi.org/10.1039/B412375A. 